\title{
CURRENT DRUGS WITH POTENTIAL FOR COVID-19 TREATMENT
}

\author{
Anish Rajput \\ Department of Life Sciences and Biotechnology, \\ Graphic Era (Deemed to be) University, Dehradun, Uttarakhand 248002, India \\ Soumya Srivastava \\ Department of Life Sciences and Biotechnology, \\ Graphic Era (Deemed to be) University, Dehradun, Uttarakhand 248002, India \\ Mayank Chaurasia \\ Department of Life Sciences and Biotechnology, \\ Graphic Era (Deemed to be) University, Dehradun, Uttarakhand 248002, India
}

\begin{abstract}
The novel coronavirus identified as 2019-nCoV has been declared as a pandemic, by the World Health Organization (WHO). It is an outbreak of respiratory illness originated in Wuhan, the capital of Hubei province, China in 2019 and has spread to other countries all over the World. SARS-CoV-2 is the seventh identified coronavirus and the most lethal found to infect humans. While the other six, SARS-CoV, MERS-CoV,229E, HKU1, NL63, and OC43 produce causes mild to severe respiratory illness. In this review, we focus, to enlist the nature, genetic makeup, extent of lethality, and mainly the potent drugs that are in clinical trials for the treatment of COVID-19. The article includes drugs, combinations of drugs that might become the vaccine for the treatment of COVID-19. It also enlists the national and international companies, private sectors, and nonprofit organizations that are working at a fast pace to develop and market the vaccine worldwide. Researchers all over the globe are collaborating to produce combinations of drugs to shorten the treatment period with more potent and effective drugs for the treatment of coronavirus.
\end{abstract}

Keywords-COVID-19, Potent drug, SARS-CoV-2, Antiviral drugs, mRNA vaccine, DNA vaccine

\section{INTRODUCTION}

Corona viruses are the etiological agent of respiratory, enteric, hepatic and neurological diseases in animals and humans. Corona viruses typically affect the respiratory tracts of birds and mammals including humans. Corona virus usually seems to cause common cold flu, but they can be responsible for more severe illnesses. Scientists can easily cultivate rhinoviruses in the laboratory, but they hardly can in case of coronavirus. This makes the study of its consequences a more challenging part. Coronavirus disease
(COVID-19) is an infectious disease ranging from mild experience to the one that could be fatal[1].

The name "coronavirus" comes from the crown like projections on their surfaces. Corona in Latin means "halo" or "crown". Coronavirus are large, roughly spherical particles bulbous surface projections known as peptomers appearance more like a virion[2]. The average diameter of the virus particle is around $125 \mathrm{~nm}(.125 \mu \mathrm{m})$. The diameter of the envelope is $85 \mathrm{~nm}$ and the spikes are $20 \mu \mathrm{m}$.Its genome consist of positive sense single stranded RNA genome. The genome size for coronavirus ranges from 26.4 to 31.7 kilobases. The genome size is one of the largest among RNA viruses. Coronavirus viral classification includes Virus classification-Kingdom-Orthornavirae, PhylumPisuviricota, Class-Pisoniviricetes, Order-Nidovirales, Family-Coronaviridae, Subfamily-Orthocoronavirinae[3][7].

As humans have spread across the world, so have infectious diseases. Even in this modern era, outbreaks are nearly constant, though not every outbreak reaches pandemic level as Covid-19. Pandemics have been in concern since centuries and we are encountered by the one till date. Antonine plague (165-180), Black death (1347-1351), Cholera (1817-1923), Spanish flu (1918-1919), HIV/Aids (1981-present), SARS (2003-2004), Ebola (2014-2016), MERS (2015-present), these are the most important pandemics occurred over time[8]. The novel coronavirus was first identified in 1937, isolating one that was responsible for a type of bronchitis I birds that had the potential to devastate poultry stocks. In the 1940s and 1960s, two animal coronaviruses i.e., Mouse hepatitis virus and (MHV) and the transmissible gastroenteritis virus (TGEV) were also isolated and human coronaviruses respectively. The earliest ones studied were isolated from human patients suffering from the common cold, and later it was named human coronavirus $229 \mathrm{E}$ and human coronavirus OC43. From 2003 to 2019, there has been a huge discovery showing up different types of coronavirus including SARS-CoV in 2003, HCoV NL63 in 2004, HKU1 
in 2005, MERS-CoV in 2012, and SARS-CoV-2 in 2019. They are responsible for serious respiratory tract infection that can be mild and lethal. common cold comes under mild illnesses while lethal cases can be SARS, MERS, and COVID-19[9].

SARS-CoV-2 which causes covid-19 has been monitored by the Centres for Disease Control and Prevention (CDC) as an outbreak in 2019.CDC first identified the virus in Wuhan, China. Huanan Seafood market in Wuhan has been linked with the outbreak of Covid-19[10]. World Health Organization (WHO) declared it as a pandemic on March 11, 2020 as the virus has spread to nearly every country. The first case of coronavirus was registered on 17 November 2019 in Hubei in China. Now the coronavirus cases have reached to 7,342,777, all the World with 414,1216 death cases and $3,620,189$ recovered cases. India reported its first case on $30^{\text {th }}$ January 2020. India has a total of 276,583 total cases with $+1,805$ new cases, total death cases of 7,745 with +26 new deaths till date.

Precaution and management include, if symptoms are seen go to the doctor at once with safety measures wearing masks and gloves, quarantine yourself and follow the measures taken by the government, supportive care, social distancing, and selfisolation.

Researchers worldwide are working around the clock to find vaccine against SARS-CoV-2, the lethal of the coronavirus that is causing havoc all over the world. On average it takes 10 years to develop a vaccine. Already many vaccines are against SARS-CoV-2 are in clinical trials[11]. A flurry of small and rapidly designed clinical trials of proposed COVID-19 drugs has left the medical community with as many questions as answers on the safety and efficacy of these agents. Many companies all over the world collaborating for the production of the vaccines as soon as possible. Vaccine production would base on experiments with potent drugs, combinations of drugs that are expected to posses' antiviral properties and causes fast and rapid recovery. Refer to the table given below for the drugs that consists of potential to fight the novel coronavirus.

\begin{tabular}{|c|c|}
\hline S.No. & Potential Therapeutics Against COVID 19 \\
\hline 1. & $\begin{array}{l}\text { Remdesivir (GS-5734) } \\
\text { - Broad Spectrum Antiviral Drug used for Ebola } \\
\text { Treatment } \\
\text { - } \quad \text { CT in progress for activity against COVID } 19\end{array}$ \\
\hline 2. & $\begin{array}{l}\text { Chloroquine and Hydroxychloroquine } \\
\text { - Antimalarial Drugs } \\
\text { - Hydroxychloroquine showed greater efficacy in vitro. } \\
\text { RCT in progress for in vivo analysis. }\end{array}$ \\
\hline 3. & $\begin{array}{l}\text { Lopinavir-Ritonavir: Kaletra or Aluvia } \\
\text { - } \quad \text { RCTs in progress } \\
\text { - } \quad \text { CDC has found them ineffective in trials so far. } \\
\text { A combination along with INF alpha has been certified } \\
\text { by CPAM for use against corona viruses. }\end{array}$ \\
\hline 4. & $\begin{array}{l}\text { Danoprevir (Ganovo) with Ritonavir } \\
\text { - } \quad \text { Antiviral drugs against Hepatitis C } \\
\text { - } \quad \text { Successful Clinical Trial completed by Ascetic Pharma } \\
\text { Inc. }\end{array}$ \\
\hline 5. & $\begin{array}{l}\text { Favipiravir (T-705) } \\
\text { - Japanese Antiviral Drug against influenza } \\
\text { - } \quad \text { RCT in progress. Proposed Dosage: } 600 \mathrm{mg} \text { tid with } \\
\text { 1600mg loading dose. } \\
\text { RCT assessing its efficacy along with Tocilizumab } \\
\text { under progress. }\end{array}$ \\
\hline 6. & $\begin{array}{l}\text { Sofosbuvir and Ribavirin } \\
\text { - } \quad \text { Antiviral drugs used against Hepatitis C } \\
\text { - } \quad \text { Molecular docking Results show effective ability to bind } \\
\text { with RNA dependent RNA Polymerase (RdRp). }\end{array}$ \\
\hline 7. & $\begin{array}{l}\text { Darunavir (with Cobicistat) } \\
\text { - Antiretroviral Drug used against HIV } \\
\text { - RCT in progress } \\
\text { - } \quad \begin{array}{l}\text { Proposed Dosage: 800mg Darunavir + } \\
\text { Cobicistat QD }\end{array}\end{array}$ \\
\hline 8. & $\begin{array}{l}\text { Emtricitabine and Tenofovir } \\
\begin{array}{c}\text { - } \\
\text { - }\end{array} \text { RCT in progress } \\
\end{array}$ \\
\hline 9. & $\begin{array}{l}\text { Baloxavir marboxil (Xofluza) } \\
\text { - } \quad \text { Antiviral Endonuclease Inhibitor } \\
\text { - } \quad \text { RCT in progress } \\
\text { - } \quad \text { Proposed Dosage: } 80 \mathrm{mg} \text { on day } 1,4 \text { and } 7 \\
\end{array}$ \\
\hline 10. & $\begin{array}{l}\text { Arbidol (Umifenovir) } \\
\begin{array}{cl}\text { - } & \text { Antiviral indole derivative molecule } \\
\text { - } & \text { RCT in progress }\end{array}\end{array}$ \\
\hline
\end{tabular}

Table 1: Possible Potent Drug for COVID-19

For the treatment of COVID-19 (Coronavirus disease, 2019) which is caused by SARS-CoV-2, the above-mentioned drugs are count as a possible potent drug. Few of them are under clinical trials. Few of the drugs are giving to the COVID-19 positive patients under serious conditions because of some common symptoms like fever etc. Drugs like Chloroquine and Hydroxychloroquine are giving positive result in reducing fever and slowing down coronavirus in some reported cases[12]. 


\section{POTENT DRUGS}

2.1 Remdesivir (GS-5734) Remdesivir, or GS-5734, is similar to the adenosine triphosphate first indicated as an anticipated cure for Ebola and it also has the potential for the treatment a variety of RNA viruses[13]. It's operation is also being illustrated in 2017 in addition to the coronavirus family of viruses, such as SARS CoV and MERS CoV[2]. Remdesivir is also being evaluated for SARS-CoV treatments, the coronavirus responsible for COVID-19[14].

Mode of Action: Remdesivir has a similar structure, an analog nucleoside which is used to inhibit RNA polymerase action[15]. No further incorporation of new nucleotides occurs thus terminating RNA transcription by incorporating into RNA[15]. Viruses with RNA polymerase mutation have increased partial resistance to Remdesivir, and have been studied to be less infectious [15]. There is not much knowledge about pharmacological actions. In the Ebola clinical phase, researchers analysed the change in the stage of liver enzymes that can or cannot be responsible for any damage to the liver. Researchers reported that three US COVID-19 patients display a comparable increase in liver enzymes. Typical side effects of the antiviral medicine include nausea and vomiting.

2.2 Chloroquine is an aminoquinoline derivative first developed in the 1940's for the treatment of malaria. This was the only one to deal with malaria before new antimalarial drugs such as pyrimethamine, artemisinin and mefloquine were created[16], [17].

Chloroquine and its derivative:
Hydroxychloroquine is reused for the treatment of a wide condition in HIV patient, systemic lupus erythematosus and used for extraintestinal amebiasis[18]. Chloroquine is also used to treat rheumatic disease and the prophylaxis and treatment of zika virus[18]-[20]. Reportedly chloroquine is under clinical trial for COVID-19 treatment[21].

Mode of Action: Heme polymerase action is inhibited in malarial trophozoites by the chloroquine, which inhibits heme formation to hemozoin. The accumulation of toxic heme results in Plasmodium species destroying the parasite[22]. The passive diffusion of chloroquine through the cell membrane, endosomes, lysosomes and Golgi vesicles, where it is protonated, results in an increased $\mathrm{pH}[23]$, [24]. This increased $\mathrm{pH}$ scale in endosomes prevents the virus particles from using their binding activity to host cells to prevent fusion and cell entry[25]. At the stage of ACE-2 expression, chloroquine is not effective over the cell surface, however, it inhibits ACE-2 terminal glycosylation, SARS-CoV, and SARS-COV 2 target the cell receptor. ACE-2 is no longer glycosylated, therefore entry is prohibited and may not be effective in interacting with the SARS-CoV 2 spike protein[25]. Drug overdose can cause nausea, cardiovascular collapse vomiting, shock, cardiac arrest and hypokalaemia.

2.3 Hydroxychloroquine A racemic combination consisting of hydroxychloroquine enantiomers $\mathrm{R}$ and $\mathrm{S}$ is similar to chloroquine equally as aminoquinoline[26]. It is applied to treat mild malaria, rheumatoid arthritis. SARS-CoV 2 patient is treated with both hydroxychloroquine and chloroquine[23]. A recent study revealed a fatal risk in COVID-19 patients when treated with hydroxychloroquine[27]. Hydroxychloroquine in humans generates similar action of lysosomes almost as much as plasmodia. Changes in lysozyme $\mathrm{pH}$ shift the behaviour toward self-antigenic presentation in autoimmune disease and modify plasmodia 's ability to proteolyze haemoglobin to fulfil energy requirements[28]. Hydroxychloroquine may also lead to extreme hypoglycaemia, so it is recommended that diabetic patients show their blood glucose level. Hydroxychloroquine is positive for malaria in those regions where chloroquine resistance has been reported.

Method of Action: We are still not sure of the actual mode of action of hydroxychloroquine. But it is proved that the accumulation of hydroxychloroquine inside the malaria parasite lysosomes results in the $\mathrm{pH}$ increase in the vacuole. This interferes with the function of Parasite haemoglobin proteolyzes capacity, stopping the parasite's replication and natural growth[28]. Hydroxychloroquine also facilitates the accumulation of beta hematin as a toxic product by the impediment of heme polymerase. Hydroxychloroquine prevents the dimerization of MHC class II alpha and beta chain, which in effect prevents the processing and presentation of antigens, decreasing the inflammatory response as a result of increased $\mathrm{pH}$ levels within the organelle[28]. An increase in the $\mathrm{pH}$ within the vesicles leads to the alter in the recycling, oh MHC complexes are introduced within the cell outer surface. Self-binding peptide attaches to MHC complex with less affinity and they probably tend to less be presented on autoimmune $\mathrm{T}$ cell. Hydroxychloroquine minimizes the release of cytokinin like tumor necrosis factor and interleukin-1[28]. The increased $\mathrm{pH}$ in endosomes stops the attachment of virus particles to the host cell receptor and prevents entry into the cell. 


\section{International Journal of Engineering Applied Sciences and Technology, 2020 \\ Vol. 5, Issue 2, ISSN No. 2455-2143, Pages 368-378 \\ Published Online June 2020 in IJEAST (http://www.ijeast.com)}

Hydroxychloroquine inhibits ACE-2 terminal glycosylation to prevent the receptor that allows the entry of SARS-CoV and SARS-CoV 2 targets into the cell[24], [25]. Because ACE 2 does not glycosylate, it may be less efficient to interact with spike protein of SARS CoV 2 and further inhibit the virus from entering[25]. High dosage of the drug results in drowsiness, cardiovascular collapse, headache, hypokalaemia and a sudden respiratory and cardiovascular stroke.

2.4 Lopinavir restrains vital enzyme activity for the HIV lifecycle. Lopinavir and other protease inhibitors are vulnerable to interfering with other drugs. As pharmacodynamics and pharmacokinetic interaction between drugs are usual, precaution must be taken when prescribing lopinavir to the patient who is taking other medications. Deadly, hepatotoxicity and pancreatitis were reported in a patient, and the potential risk of these interventions must be closely tested during the treatment period.[29].

Mode of Action: HIV's life cycle is marked by three stages: assembly, creation and packaging of vital virus components, budding and forming a lipid envelope by budding out the plasma membrane and maturation, while the viral particle shapeshifts the structure and becomes infectious[30]. In between the life cycle Gag poly proteins, alongside the product of its proteolysis coordinate these stages and characteristics the basic structural protein of the virus. The HIV-1 protease enzyme, a dimeric aspartic protease, is capable of cleaving the Gag polyprotein and plays a fundamental role in one of several aspects of the life cycle of HIV viruses[31]. Lopinavir functions as a protease enzyme inhibitor of HIV -1. Its structure is based entirely on the "peptidomimetic" principle. Whereas the molecule contains a hydroxyethylene scaffold that structurally similar to the regular peptide linkage (cleaved by HIV protease) it cannot be cleaved by itself[32]. Thus, by ceasing the activity of HIV -1 protease and hence the proteolysis of gag polyprotein, lopinavir results in the production of juvenile, no infectious virus particles.

2.5 Ritonavir inhibits protease against human immunodeficiency virus type-1 (HIV-1). An enzyme- HIV-1 protease required for the proteolytic cleavage of the viral polypeptide precursor into the functional protein found in HIV-1 infectious. Enzyme inhibition is done when Ritonavir binds to the enzyme's active site causing immature and inactive viral protein to form due to viral polypeptide cleavage. Inhibition of protease is almost constant when used in combination with two or more anti-HIV medications. Modern protease inhibition allowed the use of low dose Ritonavir to increase pharmacokinetic exposure through metabolism inhibition linked to the cytochrome P450 CYP3A5 pathway or enzyme[33].

Mode of Action: The inhibition caused by Ritonavir is due to the restriction of the viral protein enzyme essential for the cleavage of structural and replicative proteins typically formed from major HIV genes like gag, pol. The core protein and nucleocapsid is encoded by the gag Gene ribonuclease $\mathrm{H}$, integrase, protease, and reverse transcriptase is encoded by the pol gene. The polfirst encoded protein is translated into a large precursor polypeptide, gag-pol and to form the complement protein it is needed to be cleaved by HIV protease[34]. The Ritonavir prevents the gagpol polypeptide from cleavage due to the formation of non-infectious and immature viral protein. Cytochrome p450 CYP3A4 isoenzyme found and inhibited by ritonavir in both the liver and intestines tract[34]. A Class II ligand that fits the active site of CYP3A4 and binds irreversibly to the heme ion via thiazole nitrogen, thereby reducing the protein's redox potential and preventing its reduction together with the redox partner cytochrome p450 reductase[35]. This medication may have side effects such as rash, vomiting, nausea, stomach pain and diarrhoea.

2.6 Danoprevir was studied during the trial for the treatment of hepatitis C[36]. Danoprevir is an inhibitor of the protease NS3/4A. Because of the potential involvement in viral replication and suppressive effects on host response to viral infection make the HCV NS3/4A protease an attractive target. Danoprevir is found to be the new class of drugs used to treat $\mathrm{HCV}$ due to the $\mathrm{HCV}$ protease inhibition effect[37]-[40].

2.7 Favipiravir (T-705) Favipiravir functions as a prodrug and intracellularly undergoes ribosylation and phosphorylation to become the active favipiravir-RTP. Favipiravir-RTP binds RNAdependent polymerase (RdRp) and inhibits it, which eventually prevents viral transcription and replication[41]-[43].

Mode of Action: Favipiravir is novel in comparison to current influenza antivirals mainly preventing entry and exit of the virus from cells. The active favipiravir-RTP inhibits RNA polymerase selectively and prevents viral genome replication. 


\section{International Journal of Engineering Applied Sciences and Technology, 2020 Vol. 5, Issue 2, ISSN No. 2455-2143, Pages 368-378 \\ Published Online June 2020 in IJEAST (http://www.ijeast.com)}

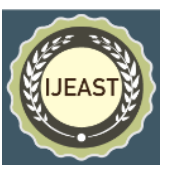

There are several theories about how favipiravirRTP interacts with RNA-dependent RNA polymerase (RdRp). Some research has shown that when favipiravir-RTP is integrated into a nascent RNA strand it prevents elongation of the RNA strand and proliferation of virus. Studies have also found that the presence of purine analogs that limit the antiviral activity of favipiravir, suggesting competition between favipiravir-RTP and purine nucleosides for RdRp binding[41]'[42]. Although favipiravir initially designed to deal with influenza, the RdRp catalytic domain (favipiravir primary target) is thought to be similar for other RNA viruses. This retained $\mathrm{RdRp}$ catalytic domain contributes to broad-spectrum coverage of favipiravir. T-705 (Favipiravir) Induces Lethal Mutagenesis in Influenza A H1N1Viruses in Vitro[41].

2.8 Sofosbuvir, This drug is used in combination therapy with different antiviral medicines for co-infected (chronic hepatitis $\mathrm{C}$ virus infected patients with $\mathrm{HCV}$ genotypes 1-6) patients with HCV (Hepatitis C virus) and HIV.[44], [45]. Often used in combination therapy are ribavirin and peg-interferon alfa, it depends on the severity of the cirrhosis or decompensation. The combination of Ledipasvir contributes to the treatment of genotypes $1,4,5$ or 6 without cirrhosis or with compensated cirrhosis; in combination with Ribavirin for the treatment of genotype 1 with decompensated cirrhosis; or in combination with Ribavirin for the treatment of genotype 1 or 4 infections which are recipients of liver transplants without cirrhosis or with compensated cirrhosis[46]-[48].

Mode of Action: Sofosbuvir, in particular, inhibits HCV NS5B (Non-structural Protein 5B) RNAdependent RNA polymerase as a nucleotide analog inhibitor. Followed by the formation of pharmacologically active Uridine analog triphosphate (GS461203), by intracellular metabolism. With the help of Non-structural protein 5B polymerase, Sofosbuvir get incorporates into Hepatitis C Virus RNA and acts as a chain terminator[49]. Common side effects may include fatigue, headache, nausea, sleeplessness, exhaustion, itching, anemia and rash.

2.9 Ribavirin is an artificial guanine nucleoside that interferes with virus m-RNA production to treat hepatitis-c and viral haemorrhagic fever[50]. The 9 distinct type genotype has single-stranded RNA virus with 1 genotype being the most common in the United States and affecting 72 percent of all Chronic
$\mathrm{HCV}$ patients. Ribavirin may only be effective in the early phase of viral haemorrhagic fever, including Venezuela haemorrhagic fever, hantavirus infection, haemorrhagic fever in the Crimean Congo, and Laser fever. Metabolization of Ribavirin prodrug into nucleoside analog blocks viral RNA synthesis and viral mRNA capping[51]. Ribavirin induces increase in the level of mutation in genome of numerous RNA viruses. The class represents the nucleoside antimetabolite drug, which interferes with the cloning of the viral genetic material. Because of its structural similarity Ribavirin can block RNA dependent RNA polymerase[52].

Mode of action: The Guanosine analog (ribonucleic) is the one that inhibits the synthesis of viral RNA and m-RNA capping, thus making nucleoside inhibitor. A prodrug Ribavirin that resembles the nucleotides of purine RNA when metabolized. The metabolized form interferes with RNA metabolism during viral replication. Ribavirin and PEG interferon alpha-2 A dual therapy are associated with flu-like symptoms such as insomnia, irritability and depression[53][55].

2.10 Darunavir acts as a protease inhibitor that is used with other HIV protease-inhibiting drugs such as ritonavir for positive HIV-1 infection management. As a second generation protease inhibitor, Darunavir has been formulated to combat resistance towards general HIV therapy, as it is a second generation protease inhibitor[56]-[58]. The FDA initially allowed this in 2006. Many scientists are investigating Darunavir and its paths and mechanisms of action for a feasible cure for SARSCoV-2 the coronavirus accountable for COVID19[59], [60]. Many clinical trials will be completed in August 2020 and are underway.

Mode of Action: The cleavage of gag-pol is stopped due to the inhibition of the HIV protease enzyme due to the formation of the inhibitor enzyme complex. In turn, they produce immature viral particles that are not infective[61], [62]. Effects of therapy consist of vomiting, nausea, nasopharyngitis, stomach discomfort, constipation, alkaline phosphate, rash, hypercholesterolemia, hypertriglyceridemia, etc.

2.11 Cobicistat, Available under the name Tybost (formerly GS-9350) and used for HIV treatment. Although it does not have any anti-HIV properties, but inhibits cytochrome P450 3A isoforms (CYP3A), cobicistat is considered a pharmacokinetic enhancer and thus increases the systemic exposure of coadministered agents that are subsequently metabolized by CYP3A enzymes[63]. Cobicistat has 


\section{International Journal of Engineering Applied Sciences and Technology, 2020 Vol. 5, Issue 2, ISSN No. 2455-2143, Pages 368-378 \\ Published Online June 2020 in IJEAST (http://www.ijeast.com)}

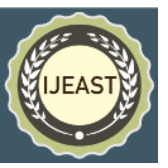

shown increased systemic exposure of Darunavir and Atazanavir in combination with other antiretroviral agents in the treatment of HIV-1 infection[64]. There should be few parameters to characterize a better drug, such as increasing systemic antiretroviral exposure without increasing dosage allowing for and decreasing side effect profile.

Mode of Action: Mechanism of inhibition of CYP3A mediated metabolism by cobicistat led to the increase in systemic exposure of CYP3A substrate Darunavir and Atazanavir and therefore subsequently increase in antiviral activity at the lower dosage. This is the reason Cobicistat is a mechanism-based inhibitor although it does not have any anti-HIV activity of its own[65], [66]. The most frequently reported adverse reactions seemed to be jaundice, ocular icterus and nausea.

2.12 Emtricitabine, known as the Nucleoside Reverse Transcriptase Inhibitor (NRTI) and a cytidine analogue, it is indicated in the treatment of HIV infection in adults and for people at higher risk to use emtricitabine in conjunction with Tenofovir alafenamide[67], [68]. The drug operated on the principle of blocking HIV RNA transcription to DNA by stopping the HIV reverse transcriptase[69]. Nausea, vomiting, stomach pain, diarrhoea, and running nose can be side effects.

2.13 Tenofovir is a potent positive drug that has been clinically tested against hepatitis B virus, HIV and herpes simplex virus 2. It's an acyclic compound (molecule don't form any ring) nucleotide diester analog of adenosine monophosphate (AMP)[70]. Tenofovir alafenamide is developed as a novel prodrug for the enhancement in renal safety. Comparison on the bases of stability tenofovir alafenamide is more stable than tenofovir disoproxil in plasma[71].

Method of Action: it's a DNA chain termination process in which tenofovir disoproxil fumarate got hydrolyzed to tenofovir, which gets phosphorylated after to tenofovir diphosphate when competing with the natural substrate deoxyadenosine 5'-triphosphate, HIV-1 reverse transcriptase activity got inhibited by tenofovir diphosphate[72]. Nausea, headache, upset stomach, diarrhea and running nose may be common side effects, etc.

2.14 Baloxavir marboxil (Xofluza), The cap-dependent endonuclease activity of the virus polymerase complex is inhibited by Baloxavir marboxil as an influenza therapeutic drug[73].
Method of Action: The inhibition process mainly involves capping so it called cap snatching, the virus obtains short capped primers from the host cell RNA transcripts which are required for the synthesis of its viral mRNAs through polymerase catalysation. When a polymerase subunit binds to the 5'-caps of the host pre-mRNAs, then cleavage occurs after 1013 nucleotides by polymerase's endonuclease activity[74]. Usually reported side effects include diarrhoea, common cold, headache, nausea, and bronchitis.

2.15 Arbidol (Umifenovir), Umifenovir act binate like host targeting agents and direct antiviral for the prophylaxis of influenza and different respiratory infections[75]. The potency of this drug's effect as antiviral thru a couple of pathways led scientist to investigate the range of its use in the medication of enveloped and non-enveloped RNA and DNA viruses, which includes Zika virus[76], Lassa Virus[77], Foot and mouth disease[78], Ebola virus[77], Hantan virus, hepatitis $B$ and $C$ viruses and reovirus[75]. Its show effects via both direct-acting means destroying or inactivating the virus and by inhibiting the stages of the viral life cycle.

Method of Action: Inhibition took place during the endocytosis of the virus which means take-up of the virus through endocytosis or in simpler words inhibition of attachment of virus membrane and host cell membrane. And this prevents viral entry and protects it from infection[79]. After seeing Umifenovir (Arbidol) mechanism and involving pathways, it can serve as an effective drug for COVID-19 in combination with previous HIV drugs, scientists and several research institutes around the globe are moving on this drug.

\section{DRUG DEVELOPMENT REPORT}

In the pandemic of COVID-19 most of the government, private, non-profit organizations tied up together and create a common platform to share updates regarding the COVID-19 vaccine and strategies the procedure for treatment.

Majority of the organizations biotechnological, pharmacological and bio-pharmaceuticals agencies bought together to do a collaborated work by National Institute of Health (NIH) some listed are Centre for Disease Control and Prevention, the health and human service office of the assistant secretary for preparedness and response, the US food and drug administration and all other agencies worldwide share their contribution and efforts in response to the COVID-19 pandemic. 
All the agencies are in the urge to find a cure or treatment, to make it a smooth effective regulated procedure, clinical trials to curb the duration of treatment as short as possible to outlaw the upcoming burden faced during the COVID-19 pandemic until the vaccine is available. To manage COVID19 and such pandemic soon, these are strategies under the COVID-19 Accelerating Therapeutic intervention and vaccine (ACTIV) partnership[80].

Researchers in the world are indulging in finding the effective medicine that can shorten the treatment period and, in a way, Remdesivir is published as a first, as of outcome of largely performed clinical trials. The drug somehow relieved and out-pressured the COVID-19 situation in many countries but not as effective as much that it can be called a cure for COVID-19.

Many nonprofit organizations, private firms conducting a clinical trial of efficient combinations of anti-viral drugs to provide a more effective treatment. In a way, Glenmark can be credited for conducting another drug combination of Favipiravir and Umifenovir that is under the third clinical phase, after getting expected results in India and is under the regulation of Indian Regulatory authority Drug Controller General of India (DGCI) august 2020[81].

Lopinavir and ritonavir are recommended by the experts to be effective and potent treatment as an anti-COVID-19 agent in china, with the following results among many countries these two is being used as a positive control. As among other anti-viral drugs Tenofovir alafenamide and emtricitabine they also inhibit the reverse transcriptase, which is prescribed for the treatment of hepatitis B virus and HIV infection. As of the following researches, these studies turn the usage of these drugs to treat COVID-19 patients.

\begin{tabular}{|c|c|c|c|}
\hline & Developer & Properties & $\begin{array}{l}\text { Development } \\
\text { status }\end{array}$ \\
\hline $\begin{array}{l}\text { mRNA- } \\
1273\end{array}$ & Moderna and NIAID & mRNA vaccine & Phase 2 \\
\hline BNT162 & BioNTech and Pfizer & mRNA vaccine & Phase $1 / 2$ \\
\hline INO-4800 & $\begin{array}{l}\text { Inovio } \\
\text { Pharmaceuticals }\end{array}$ & DNA vaccine & Phase 1 \\
\hline AZD1222 & $\begin{array}{l}\text { University of Oxford } \\
\text { and AstraZeneca }\end{array}$ & $\begin{array}{l}\text { Adenovirus } \\
\text { vaccine }\end{array}$ & Phase $2 b / 3$ \\
\hline Ad5-nCoV & CanSino Biologics & $\begin{array}{l}\text { Adenovirus } \\
\text { vaccine }\end{array}$ & Phase 2 \\
\hline Unnamed & $\begin{array}{l}\text { Wuhan Institute of } \\
\text { Biological Products } \\
\text { and Sinopharm }\end{array}$ & $\begin{array}{l}\text { Inactivated } \\
\text { virus }\end{array}$ & Phase $1 / 2$ \\
\hline Unnamed & $\begin{array}{l}\text { Beijing Institute of } \\
\text { Biological Products } \\
\text { and Sinopharm }\end{array}$ & $\begin{array}{l}\text { Inactivated } \\
\text { virus }\end{array}$ & Phase $1 / 2$ \\
\hline PiCoVacc & Sinovac & $\begin{array}{l}\text { Inactivated } \\
\begin{array}{l}\text { virus, plus } \\
\text { adjuvant }\end{array}\end{array}$ & Phase $1 / 2$ \\
\hline Unnamed & $\begin{array}{l}\text { Institute of Medical } \\
\text { Biology and Chinese } \\
\text { Academy of Medical } \\
\text { Sciences }\end{array}$ & $\begin{array}{l}\text { Inactivated } \\
\text { virus }\end{array}$ & Phase 1 \\
\hline
\end{tabular}

\begin{tabular}{|l|l|l|l|}
\hline $\begin{array}{l}\text { NVX- } \\
\text { CoV2373 }\end{array}$ & Novavax & Protein subunit & Phase 1/2 \\
\hline
\end{tabular}

Table 2: COVID-19 vaccines under clinical trials[11]

Some of the pharma companies that can be listed among worldwide in finding the COVID-19 vaccine are Amgen, Pfizer, AbbVie, KSQ Therapeutics, GlaxoSmithKline, Eli lily and company, AstraZeneca, Merck co. , Roche, Vir Biotechnology, Evote, and many others that partner with each other or some with the government agencies.

\section{CONCLUSION}

In the current situation of the COVID-19 pandemic outbreak in the world, which continues to evolve and spread. The organizations and researchers are keen on finding the potent cure and finding a way to detect the disease more rapidly to screen in the infected areas. Till now RT-PCR is a way to detect the coronavirus and rapid detection kits is utilized by the organizations to screen the virus with the community. In the early phase of the research, the agents used to treat COVID-19, which is in vogue are in total 15 drugs that are being used for the treatment, some of them are outlawed and some are in still use, and other in clinical trials. Lopinavir and Ritonavir are used to treat the viral infection as stated by the experts in China which are also used as a positive control worldwide.

A flurry of small and rapidly designed clinical trials of proposed COVID-19 drugs has left the medical community with as many questions as answers on the safety and efficacy of these agents. Hydroxychloroquine is stated as an effective agent to treat COVID-19 but has a fatal risk of health. Favipiravir and Umifenovir that is under the third clinical phase, after getting expected results in India and is under the regulation of Indian Regulatory authority Drug Controller General of India (DGCI) August 2020.

Tenofovir alafenamide and emtricitabine also inhibit the reverse transcriptase, which is prescribed for the treatment of the hepatitis B virus and HIV infection is also used for the COVID-19 treatment. Among the following clinical trials over vaccine is fueling the hope, University of Oxford and AstraZeneca is developing an adenovirus vaccine which is in a phase $2 b / 3$ of clinical trials.

While the vaccine is under clinical trials researchers are also finding a way to short the treatment period by a combination of drugs that are more potent and effective for the treatment of the coronavirus. Apart from all the researches during the pandemic government is providing the guidelines to stop the community spread by proper sanitization, social distancing, and taking necessary precautions that help common people to fight the disease. 


\section{ACKNOWLEDGEMENT}

We would like to express our sincere gratitude to our mentors, Last but not the least, we would like to thank our family for support.

Author contributions: MC suggested the topic, concept, design and writing the first-hand manuscript. SS and AR did extensive literature search and the final evaluation. AR and SS provided the technical guide. All authors read and approved the final manuscript.

Conflict of Interest: The authors declare no conflict of interest.

\section{REFERENCES}

[1] World Health Organization, "Coronavirus Disease (COVID-19),” 2019. [Online]. Available: https://www.who.int/health-

topics/coronavirus\#tab=tab_3. [Accessed: 09-Apr2020].

[2] 2017 Shahul S,Tung A, Minhaj M, Nizamuddin J, Wenger J, Mahmood E, Mueller A,Shaefi S, Scavone B, Kociol R D, Talmor D, Rana S, "HHS Public Access," Physiol. Behav., vol. 176, no. 10, pp. 139148, 2017, doi: 10.1016/j.physbeh.2017.03.040.

[3] D. Tomasi, "Coronavirus disease ( COVID-19). A socioepidemiological review," Vermont Acad. Arts Sci., vol. 1, pp. 1-7, 2020.

[4] P. C. Y. Woo, Y. Huang, S. K. P. Lau, and K. Y. Yuen, "Coronavirus genomics and bioinformatics analysis," Viruses, vol. 2, no. 8, pp. 1805-1820, 2010, doi: 10.3390/v2081803.

[5] C. S. Goldsmith et al., "Ultrastructural Characterization of SARS Coronavirus," Emerg. Infect. Dis., vol. 10, no. 2, pp. 320-326, 2004, doi: 10.3201/eid1002.030913.

[6] B. W. Neuman et al., "Supramolecular Architecture of Severe Acute Respiratory Syndrome Coronavirus Revealed by Electron Cryomicroscopy," J. Virol., vol. 80, no. 16, pp. 7918-7928, 2006, doi: 10.1128/jvi.00645-06.

[7] H. J. Maier, E. Bickerton, and P. Britton, "Coronaviruses: Methods and protocols," Coronaviruses Methods Protoc., vol. 1282, no. 1, pp. 1-282, 2015, doi: 10.1007/978-1-4939-2438-7.

[8] S. Front, "History's Deadliest Pandemics: From
Antonine Plague To COVID-19," Anc. Hist. Encycl., 2020 .

[9] K. Amgain, S. Neupane, and L. Panthi, "Myths vs . Truths regarding the Novel Coronavirus Disease ( COIV- 2019 ) Outbreak," vol. 3, no. 1, pp. 1-6, 2020.

[10] Business Insider India, "A coronavirus that originated in Wuhan, China," 2020.

[11] A. Mullard, "World Report COVID-19 vaccine development pipeline gears up," Lancet, vol. 395, no. 10239 , pp. 1751-1752, doi: 10.1016/S01406736(20)31252-6.

[12] A. Kumar, A. Singh, A. Shaikh, and R. Singh, "Since January 2020 Elsevier has created a COVID-19 resource centre with free information in English and Mandarin on the novel coronavirus COVID- 19. The COVID-19 resource centre is hosted on Elsevier Connect, the company' $\mathrm{s}$ public news and information ," no. January, 2020.

[13] T. K. Warren et al., "Therapeutic efficacy of the small molecule GS-5734 against Ebola virus in rhesus monkeys," Nature, vol. 531, no. 7594, pp. 381-385, 2016, doi: 10.1038/nature17180.

[14] P. Berzosa et al., "Profile of molecular mutations in pfdhfr, pfdhps, pfmdr1, and pfcrt genes of Plasmodium falciparum related to resistance to different anti-malarial drugs in the Bata District (Equatorial Guinea)," Malar. J., vol. 16, no. 1, pp. 110, 2017, doi: 10.1186/s12936-016-1672-0.

[15] M. L. Agostini et al., "Coronavirus susceptibility to the antiviral remdesivir (GS-5734) is mediated by the viral polymerase and the proofreading exoribonuclease," MBio, vol. 9, no. 2, pp. 1-15, 2018, doi: 10.1128/mBio.00221-18.

[16] K. Diseases, “Chloroquine,” no. Md, 2017.

[17] S. Vandekerckhove and M. D’Hooghe, "Quinolinebased antimalarial hybrid compounds," Bioorganic Med. Chem., vol. 23, no. 16, pp. 5098-5119, 2015, doi: 10.1016/j.bmc.2014.12.018.

[18] D. Plantone and T. Koudriavtseva, "Current and Future Use of Chloroquine and Hydroxychloroquine in Infectious, Immune, Neoplastic, and Neurological Diseases: A Mini-Review," Clin. Drug Investig., vol. 38, no. 8, pp. 653-671, 2018, doi: 10.1007/s40261018-0656-y.

[19] S. A. Shiryaev et al., "Repurposing of the antimalaria drug chloroquine for Zika Virus treatment and prophylaxis," Sci. Rep., vol. 7, no. 1, pp. 1-9, 


\section{International Journal of Engineering Applied Sciences and Technology, 2020 Vol. 5, Issue 2, ISSN No. 2455-2143, Pages 368-378 \\ Published Online June 2020 in IJEAST (http://www.ijeast.com)}

2017, doi: 10.1038/s41598-017-15467-6.

[20] C. Li et al., "Chloroquine, a FDA-approved Drug, Prevents Zika Virus Infection and its Associated Congenital Microcephaly in Mice," EBioMedicine, vol. 24, pp. 189-194, 2017, doi: 10.1016/j.ebiom.2017.09.034.

[21] J. Gao, Z. Tian, and X. Yang, "Breakthrough: Chloroquine phosphate has shown apparent efficacy in treatment of COVID-19 associated pneumonia in clinical studies," Biosci. Trends, vol. 14, no. 1, pp. 72-73, 2020, doi: 10.5582/BST.2020.01047.

[22] Kinam Park, "NIH Public Access," Bone, vol. 23, no. 1, pp. 1-7, 2014, doi: 10.1038/jid.2014.371.

[23] J. Ducharme and R. Farinotti, "Clinical pharmacokinetics and metabolism of chloroquine. Focus on recent advancements," Clin. Pharmacokinet., vol. 31, no. 4, pp. 257-274, 1996, doi: 10.2165/00003088-199631040-00003.

[24] M. Wang et al., "Remdesivir and chloroquine effectively inhibit the recently emerged novel coronavirus (2019-nCoV) in vitro," Cell Res., vol. 30 , no. 3, pp. $269-271,2020$, doi: $10.1038 / \mathrm{s} 41422-$ 020-0282-0.

[25] M. J. Vincent et al., "Chloroquine is a potent inhibitor of SARS coronavirus infection and spread," Virol. J., vol. 2, pp. 1-10, 2005, doi: 10.1186/1743-422X-269.

[26] A. McLachlan, S. Tett, D. Cutler, and R. Day, "Disposition of the enantiomers of hydroxychloroquine in patients with rheumatoid arthritis following multiple doses of the racemate.," Br. J. Clin. Pharmacol., vol. 36, no. 1, pp. 78-81, 1993, doi: 10.1111/j.1365-2125.1993.tb05897.x.

[27] J. Yazdany and A. H. J. Kim, "Use of Hydroxychloroquine and Chloroquine During the COVID-19 Pandemic: What Every Clinician Should Know," Ann. Intern. Med., no. March, pp. 19-21, 2020, doi: 10.7326/m20-1334.

[28] R. I. Fox, "Mechanism of action of hydroxychloroquine as an antirheumatic drug," Semin. Arthritis Rheum., vol. 23, no. 2, pp. 82-91, 1993, doi: 10.1016/S0049-0172(10)80012-5.

[29] E. J. Arts and D. J. Hazuda, "HIV-1 antiretroviral drug therapy," Cold Spring Harb. Perspect. Med., vol. 2, no. 4, 2012, doi: 10.1101/cshperspect.a007161.

[30] W. I. Sundquist and H. G. Kräusslich, "HIV-1 assembly, budding, and maturation," Cold Spring Harb. Perspect. Med., vol. 2, no. 7, 2012, doi: 10.1101/cshperspect.a006924.

[31] AIDS INFO, "HIV Overview - The HIV Life Cycle," Aidsinfo.Nih.Gov, p. 1, 2013.

[32] E. De Clercq, "Anti-HIV drugs: 25 compounds approved within 25 years after the discovery of HIV," Int. J. Antimicrob. Agents, vol. 33, no. 4, pp. 307320, 2009, doi: 10.1016/j.ijantimicag.2008.10.010.

[33] P. J. Hughes, E. Cretton-Scott, A. Teague, and T. M. Wensel, "Protease inhibitors for patients with HIV-1 infection a comparative overview," $P T$, vol. 36, no. 6, pp. 332-345, 2011.

[34] M. W. Hull and J. S. G. Montaner, "Ritonavirboosted protease inhibitors in HIV therapy," Ann. Med., vol. 43, no. 5, pp. 375-388, 2011, doi: 10.3109/07853890.2011.572905.

[35] I. F. Sevrioukova and T. L. Poulos, "Structure and mechanism of the complex between cytochrome P4503A4 and ritonavir," Proc. Natl. Acad. Sci. U. S. A., vol. 107, no. 43, pp. 18422-18427, 2010, doi: 10.1073/pnas. 1010693107 .

[36] E. J. Gane et al., "Oral combination therapy with a nucleoside polymerase inhibitor (RG7128) and danoprevir for chronic hepatitis $\mathrm{C}$ genotype 1 infection (INFORM-1): A randomised, double-blind, placebo-controlled, dose-escalation trial," Lancet, vol. 376, no. 9751, pp. 1467-1475, 2010, doi: 10.1016/S0140-6736(10)61384-0.

[37] K. P. Romano et al., "The molecular basis of drug resistance against hepatitis $\mathrm{C}$ virus NS3/4A protease inhibitors," PLoS Pathog., vol. 8, no. 7, p. 22, 2012, doi: 10.1371/journal.ppat.1002832.

[38] M. Irshad, P. Gupta, and K. Irshad, "Molecular targeting of antiviral drugs used against hepatitis $\mathrm{C}$ virus infection," Hepatoma Res., vol. 4, no. 6, p. 23, 2018, doi: 10.20517/2394-5079.2018.25.

[39] L. Chatel-Chaix, M. Baril, and D. Lamarre, "Hepatitis C virus NS3/4A protease inhibitors: A light at the end of the tunnel," Viruses, vol. 2, no. 8, pp. 1752-1765, 2010, doi: 10.3390/v2081752.

[40] S.-H. Chen and S.-L. Tan, "Discovery of SmallMolecule Inhibitors of HCV NS3-4A Protease as Potential Therapeutic Agents against HCV Infection," Curr. Med. Chem., vol. 12, no. 20, pp. 2317-2342, 2005, doi: 10.2174/0929867054864769.

[41] T. Furuta,Y., Komeno, T., \& Nakamuba, 


\section{International Journal of Engineering Applied Sciences and Technology, 2020 \\ Vol. 5, Issue 2, ISSN No. 2455-2143, Pages 368-378 \\ Published Online June 2020 in IJEAST (http://www.ijeast.com)}

"Polymerase Activity (\%) $100 \mu \mathrm{mol} /$ L Favipiravir Favipiravir-RMP Control," Proc Jpn Acad Ser B Phys Biol Sci., vol. 93, no. 7, pp. 449-463, 2017.

[42] S. Venkataraman, B. V. L. S. Prasad, and R. Selvarajan, "RNA dependent RNA polymerases: Insights from structure, function and evolution," Viruses, vol. 10, no. 2, pp. 1-23, 2018, doi: 10.3390/v10020076.

[43] V. Madelain et al., "Ebola Virus Infection: Review of the Pharmacokinetic and Pharmacodynamic Properties of Drugs Considered for Testing in Human Efficacy Trials," Clin. Pharmacokinet., vol. 55, no. 8, pp. 907-923, 2016, doi: 10.1007/s40262-0150364-1.

[44] W. C. Summers, "Virus Infection," Encycl. Microbiol., vol. 13, no. 1, pp. 546-552, 2009, doi: 10.1016/B978-012373944-5.00323-0.

[45] A. L. Zignego, M. Monti, and L. Gragnani, "Sofosbuvir/Velpatasvir for the treatment of Hepatitis C virus infection," Acta Biomed., vol. 89, no. 3, pp. 321-331, 2018, doi: 10.23750/abm.v89i3.7718.

[46] P. Ferenci, K. Kozbial, M. Mandorfer, and H. Hofer, "HCV targeting of patients with cirrhosis," $J$. Hepatol., vol. 63, no. 4, pp. 1015-1022, 2015, doi: 10.1016/j.jhep.2015.06.003.

[47] A. Alexopoulou and P. Karayiannis, "Interferonbased combination treatment for chronic hepatitis $\mathrm{C}$ in the era of direct acting antivirals," Ann. Gastroenterol., vol. 28, no. 1, pp. 55-65, 2015.

[48] K. H. Kim et al., "Peginterferon alpha and ribavirin combination therapy in patients with hepatitis $\mathrm{C}$ virus-related liver cirrhosis.," Korean J. Hepatol., vol. 17, no. 3, pp. 220-225, 2011, doi: 10.3350/kjhep.2011.17.3.220.

[49] A. Fung, Z. Jin, N. Dyatkina, G. Wang, L. Beigelman, and J. Deval, "Efficiency of incorporation and chain termination determines the inhibition potency of 2'-modified nucleotide analogs against hepatitis C virus polymerase," Antimicrob. Agents Chemother., vol. 58, no. 7, pp. 3636-3645, 2014, doi: 10.1128/AAC.02666-14.

[50] D. Todt, S. Walter, R. J. P. Brown, and E. Steinmann, "Mutagenic effects of ribavirin on hepatitis E virusviral extinction versus selection of fitness-enhancing mutations," Viruses, vol. 8, no. 10, pp. 1-15, 2016, doi: 10.3390/v8100283.
[51] H. S. Te, G. Randall, and D. M. Jensen, "Mechanism of action of ribavirin in the treatment of chronic hepatitis C," Gastroenterol. Hepatol., vol. 3, no. 3, pp. 218-225, 2007.

[52] H. Moreno, I. Gallego, N. Sevilla, J. C. de la Torre, E. Domingo, and V. Martin, "Ribavirin Can Be Mutagenic for Arenaviruses," J. Virol., vol. 85, no. 14, pp. 7246-7255, 2011, doi: 10.1128/jvi.00614-11.

[53] C. Yu et al., "We are IntechOpen, the world' s leading publisher of Open Access books Built by scientists , for scientists TOP $1 \%$," Intech, p. 13, 2012, doi: 10.1016/j.colsurfa.2011.12.014.

[54] M. Issur, I. Bougie, S. Despins, and M. Bisaillon, "Enzymatic Synthesis of RNAs Capped with Nucleotide Analogues Reveals the Molecular Basis for Substrate Selectivity of RNA Capping Enzyme: Impacts on RNA Metabolism," PLoS One, vol. 8, no. 9, pp. 1-12, 2013, doi: 10.1371/journal.pone.0075310.

[55] D. L. Nguyen and T. R. Morgan, "Management of adverse events during the treatment of chronic hepatitis C infection," Clin. Liver Dis., vol. 1, no. 2, pp. 54-57, 2012, doi: 10.1002/cld.33.

[56] Z. Lv, Y. Chu, and Y. Wang, "HIV protease inhibitors: A review of molecular selectivity and toxicity," HIV/AIDS - Res. Palliat. Care, vol. 7, pp. 95-104, 2015, doi: 10.2147/HIV.S79956.

[57] S. De Meyer et al., "TMC114, a Novel Human Immunodeficiency Virus Type 1 Protease Inhibitor Active against Protease Inhibitor-Resistant Viruses , Including a Broad Range of Clinical Isolates," vol. 49, no. 6, pp. 2314-2321, 2005, doi: 10.1128/AAC.49.6.2314.

[58] C. L. Tremblay, "Combating HIV resistance - focus on darunavir," vol. 4, no. 4, pp. 759-765, 2008.

[59] J. M. Sanders, M. L. Monogue, T. Z. Jodlowski, and J. B. Cutrell, "Pharmacologic Treatments for Coronavirus Disease 2019 (COVID-19) A Review," vol. 2019, 2020, doi: 10.1001/jama.2020.6019.

[60] S. Lin, R. Shen, J. He, X. Li, and X. Guo, "Molecular Modeling Evaluation of the Binding Effect of Ritonavir , Lopinavir and Darunavir to Severe Acute Respiratory Syndrome Coronavirus 2 Proteases," 2020.

[61] D. Prezista and P. D. F. Version, "Darunavir (Prezista®)."

[62] J. Pasquau and C. Hidalgo, "Características químicas 


\section{International Journal of Engineering Applied Sciences and Technology, 2020 Vol. 5, Issue 2, ISSN No. 2455-2143, Pages 368-378 \\ Published Online June 2020 in IJEAST (http://www.ijeast.com)}

, mecanismo de acción y actividad antiviral de darunavir," Enferm. Infecc. Microbiol. Clin., vol. 26, pp. 3-9, 2008, doi: 10.1016/S0213-005X(08)765479.

[63] 2020) National Center for Biotechnology Information. PubChem Database. Cobicistat, $\mathrm{CID}=25151504$,

https://pubchem.ncbi.nlm.nih.gov/compound/Cobici stat (accessed on Apr. 22, "Cobicistat."

[64] D. Press, "Evaluating the role of atazanavir / cobicistat and darunavir / cobicistat fixed-dose combinations for the treatment of HIV-1 infection," pp. 47-65, 2016.

[65] J. Seet, B. Hons, G. Medmicro, and J. Elizabeth, "Cobicistat versus Ritonavir: Similar Pharmacokinetic Enhancers But Some Important Differences/ HHS Public Access," vol. 51, no. 11, pp. 1008-1022, 2017 doi: 10.1177/1060028017717018.Cobicistat.

[66] D. Cattaneo, M. V. Cossu, G. Rizzardini, and D. Cattaneo, "Expert Opinion on Drug Metabolism \& Toxicology Pharmacokinetic drug evaluation of ritonavir ( versus cobicistat ) as adjunctive therapy in the treatment of HIV therapy in the treatment of HIV," Expert Opin. Drug Metab. Toxicol., vol. 00, no. $00, \quad$ pp. 1-9, 2019, doi: 10.1080/17425255.2019.1685495.

[67] "HEPATITIS B and RISK OF DRUG RESISTANCE WITH USE Gilead Sciences," pp. 139, 2019.

[68] A. Manuscript, "NIH Public Access," vol. 13, no. 1, pp. 65-79, 2013, doi: 10.1517/14656566.2012.642865.Combination.

[69] N. Sluis-cremer and G. Tachedjian, "Mechanisms of inhibition of HIV replication by non-nucleoside reverse transcriptase inhibitors," vol. 134, pp. 147156, 2008, doi: 10.1016/j.virusres.2008.01.002.

[70] A. M. Margolis, H. Heverling, P. A. Pham, and A. Stolbach, "A Review of the Toxicity of HIV Medications," pp. 26-39, 2014, doi: 10.1007/s13181013-0325-8.

[71] A. S. Ray, M. W. Fordyce, and M. J. M. Hitchcock, "Tenofovir alafenamide: A novel prodrug of tenofovir for the treatment of Human Immunodeficiency Virus," Antiviral Res., vol. 125, pp. 63-70, 2016, doi: 10.1016/j.antiviral.2015.11.009.
[72] H. B. Fung, E. A. Stone, and F. J. Piacenti, "Tenofovir disoproxil fumarate: A nucleotide reverse transcriptase inhibitor for the treatment of HIV infection," Clin. Ther., vol. 24, no. 10, pp. 15151548, 2002, doi: 10.1016/S0149-2918(02)80058-3.

[73] A. J. Eisfeld, G. Neumann, and Y. Kawaoka, "At the centre: Influenza A virus ribonucleoproteins," Nat. Rev. Microbiol., vol. 13, no. 1, pp. 28-41, 2015, doi: 10.1038/nrmicro3367.

[74] A. Dias et al., "The cap-snatching endonuclease of influenza virus polymerase resides in the PA subunit," Nature, vol. 458, no. 7240, pp. 914-918, 2009, doi: 10.1038/nature07745.

[75] J. Blaising, S. J. Polyak, and E. I. Pécheur, "Arbidol as a broad-spectrum antiviral: An update," Antiviral Res., vol. 107, no. 1, pp. 84-94, 2014, doi: 10.1016/j.antiviral.2014.04.006.

[76] S. L. Fink et al., "The Antiviral Drug Arbidol Inhibits Zika Virus," Sci. Rep., vol. 8, no. 1, pp. 2-10, 2018, doi: 10.1038/s41598-018-27224-4.

[77] C. E. Hulseberg et al., "Arbidol and Other LowMolecular-Weight Drugs That Inhibit Lassa and Ebola Viruses," J. Virol., vol. 93, no. 8, 2019, doi: 10.1128/jvi.02185-18.

[78] M. R. Herod et al., "The broad-spectrum antiviral drug arbidol inhibits foot-and-mouth disease virus genome replication," J. Gen. Virol., vol. 100, no. 9, pp. 1293-1302, 2019, doi: 10.1099/jgv.0.001283.

[79] J. Haviernik et al., "Arbidol (Umifenovir): A broadspectrum antiviral drug that inhibits medically important arthropod-borne flaviviruses," Viruses, vol. 10, no. 4, pp. 1-8, 2018, doi: $10.3390 / \mathrm{v} 10040184$.

[80] N. Releases, "NIH to launch public-private partnership to speed COVID-19 vaccine and treatment options," pp. 1-3, 2020.

[81] “Covid-19 treatment: Glenmark Pharma gets DCGI nod for clinical trials, shares jump," businessLine, PTI BENGALURU, 30-Apr-2020. 